\title{
Effect of ocimum gratissimum plant leaf extract concentration and annealing temperature on the structure and optical properties of synthesized zinc oxide nanoparticles
}

\author{
Rebecca Emmanuel Mfon ${ }^{1,3 *}$, Simon R. Hall ${ }^{2}$, Andrei Sarua ${ }^{1}$ \\ ${ }^{1}$ School of Physics, H.H Wills Physics Lab Tyndall Avenue, University of Bristol, \\ Bristol BS8 1TL United Kingdom, \\ ${ }^{2}$ School of Chemistry, Cannock's close, University of Bristol, \\ Bristol BS8 1TS United Kingdom, \\ ${ }^{3}$ Department of Physics Federal University of Lafia, P.M.B 146 Lafia, \\ Nasarawa State, Nigeria \\ *Corresponding author: rebecca.mfon@science.fulafia.edu.ng \\ DOI: https://doi.org/10.37134/ejsmt.vol7.1.1.2020
}

Received: 14 December 2019; Accepted: 25 January 2020; Published: 31 January 2020

\begin{abstract}
Zinc oxide nanoparticles biosynthesized using two concentrations of Ocimum gratissimum $(\mathrm{Og})$ plant leaf extracts were annealed at two different temperatures. Their UV-Vis absorbance peaks at $372 \mathrm{~nm}-375 \mathrm{~nm}$ indicate a blue shift in excitonic absorption and their optical energy band gap values were in the range $3.22 \mathrm{eV}-3.31 \mathrm{eV}$. SEM images show the nanoparticles to be polydispersed and of a wide range of sizes with smaller nanoparticles clustering around bigger micrometer- sized ones with sharp edges. An annealing temperature of $400{ }^{\circ} \mathrm{C}$ resulted in the sintering of the nanoparticles but nanoparticles annealed at $250^{\circ} \mathrm{C}$ had porous surfaces suggesting a possible use in gas sensor applications. XRD patterns show that the $\mathrm{ZnO}$ nanoparticles have the hexagonal wurtzite structure and are of good crystalline structure. Obtained crystallite sizes increased with annealing temperature and were in the range $14 \mathrm{~nm}$ to $29 \mathrm{~nm}$. FTIR spectra show phenols, amines and aldehydes as the available reducing agents involved in the nanoparticle synthesis. The photoluminescence (PL) spectra show two emission peaks: a UV emission peak at 369 $381 \mathrm{~nm}$ indicating that the zinc oxide nanoparticles exhibited band-edge photoluminescence and a green emission peak at $523 \mathrm{~nm}-538 \mathrm{~nm}$ suggesting the presence of defects from singly ionized oxygen vacancies. The PL peak intensities were dependent on the annealing temperatures with the UV- emission peaks for higher annealing temperatures exhibiting a spectral shift towards lower wavelengths. Plant leaf extracts concentration and the annealing temperatures used affect the structure and optical properties of the synthesized $\mathrm{ZnO}$ nanoparticles.
\end{abstract}

Keywords: zinc oxide nanoparticles; Ocimum gratissimum; optical spectroscopy , electron microscopy

\section{INTRODUCTION}

Zinc oxide $(\mathrm{ZnO})$ nanoparticles have electrical, optical, anticorrosive properties, antibacterial and antimicrobial properties hence their wide range of application. [1] $\mathrm{ZnO}$ nanoparticles can filter UV radiations hence serve as filters in rubber and cigarettes and hence are used in sunscreen creams [2-4]. They are used for treating skin irritation [5], surface coatings [6] and are now being considered for food preservation for use by food packaging industries [5]. Recently there are researches that show that zinc oxide nanoparticles can be an active ingredient for Nano fertilizer [7-9]. ZnO nanoparticles can be used for making solar cells, and have also been used as relative humidity sensors and light emitting diodes [1, $10]$.

Though $\mathrm{ZnO}$ nanoparticles can be synthesized by physical and chemical methods [9], their biosynthesis is now preferred because it is fast, cheap and environmentally friendly. [10,11]. Presently, biosynthesis of nanoparticles using plant leaf extracts has attracted the attention of researchers because plant leaf extracts contain flavonoids [12,13] which as glucosides [14] are water soluble plant 
metabolites [15] with reducing and stabilizing abilities therefore are effective in nanoparticle synthesis $[16,17]$. Flavonoids have an $\mathrm{OH}$ group and get converted from the enol form to the keto form, producing a reactive hydrogen atom which reduces the metallic ion into nanoparticles [18]. Plant bio-molecules enable bio - reduction even at room temperature [19], stabilise the nanoparticles they create and can even cap them discouraging agglomeration [20,21].

Zinc oxide nanoparticles have been synthesized using Aloe-vera [22], Ocimum Tenuiflorum [23], Ocimum basilicum [24], and Ocimum americana [25]. ZnO nanoparticles have also been synthesized using Ocimum gratissimum [26,27] plant leaf extracts but the reported cases used precursor materials which are different from what this present research used. Furthermore it is evident that not much has been done on the use of Ocimum gratissimum plant leaf extract for $\mathrm{ZnO}$ nanoparticle synthesis. This work therefore will hopefully provide results that will contribute to existing information on $\mathrm{ZnO}$ nanoparticles biogenic synthesis using plant leaf extract.

Ocimum gratissimum (Figure 1.), also known as African basil or clove basil is called Ntoong, Nchanwu or Efirin in different regions of Nigeria and belongs to the plant family Lamiaceae. This plant, an aromatic perennial herb is common in West Africa and also popular in India as well as in the Caribbean. Grown mostly to extract oil, Indonesians use its leaves as tea [28]. Available literature shows that it can be used for treating diseases among which are headaches, haemorrhoids and inflammation [29], pneumonia, convulsion, for keeping wound surfaces sterile [30] and for enhancing the efficacy of antibiotics [31].

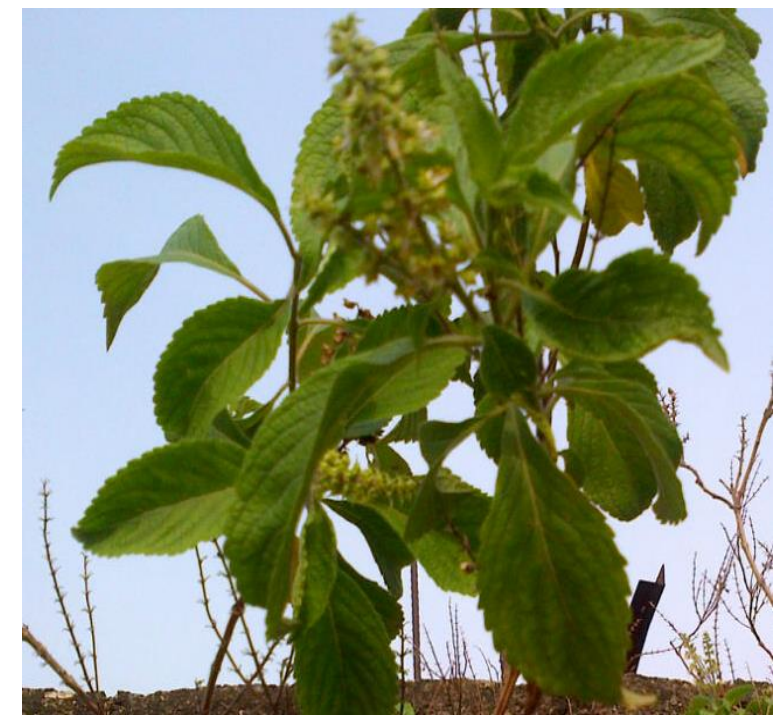

Figure 1: Ocimum gratissimum plant

In this research, zinc oxide nanoparticles were biosynthesized using concentrations of Ocimum gratissimum plant leaf extracts and the structure of the produced nanoparticles were studied using optical spectroscopy and electron microscopy.

\section{MATERIALS AND METHODS}

\section{Materials and reagents}

Zinc nitrate hexahydrate $\left(\mathrm{ZnNO}_{3} \cdot 6 \mathrm{H}_{2} \mathrm{O}\right)$ of analytical grade $(98 \%$ purity) and molecular weight 297.46 from Sigma Aldrich was used for this work. About $100 \mathrm{~g}$ of shade dried Ocimum gratissimum $(\mathrm{Og})$ plant leaves were used for making the required plant leaf extracts. The leaf extracts as well as the aqueous silver nitrate used were all made using deionized water from MILLI-Q water purifying system. 


\section{Leaf extract preparations}

The Ocimum gratissimum leaves were washed and shade-dried in air for ten days. Thereafter they were crushed to powder (Figure 2 a) and two concentrations of their leaf extracts were prepared as follows: Ten grams of dried and grinded Ocimum gratissimum leaves were boiled in $200 \mathrm{ml}$ of distilled water for 30 mins. The resulting extract was filtered and cooled to room temperature and labelled Og I. The same procedure was repeated using 30 grams of the grinded Ocimum gratissimum leaves in same volume of deionised water as before and this second solution was labelled Og II. The concentration of Og II leaf extract is greater than that of Og I leaf extract. These two plant leaf extracts were then stored in a refrigerator at $4{ }^{\circ} \mathrm{C}$ till required for the synthesis.

\section{Zinc oxide nanoparticles synthesis}

The synthesis of the zinc oxide nanoparticles was done using a method described by Sidra [8] but with the addition of prepared Ocimum gratissimum plant leaf extract. $50 \mathrm{ml}$ of $\mathrm{Og}$ I was first heated in a beaker placed in a silicon oil-bath to $75{ }^{\circ} \mathrm{C}$. At this temperature $5 \mathrm{~g}$ of zinc nitrate hexa-hydrate $\left(\mathrm{ZnNO}_{3} \cdot 6 \mathrm{H}_{2} \mathrm{O}\right)$ was poured into the hot leaf extract solution and stirred until all the $\mathrm{ZnNO}_{3} \cdot 6 \mathrm{H}_{2} 0$ salt dissolved. The $\mathrm{ZnNO}_{3} .6 \mathrm{H}_{2} 0$ salt-leaf extract mixture was boiled for some time under continuous stirring until a browncoloured paste (Figure 2 b) was obtained.

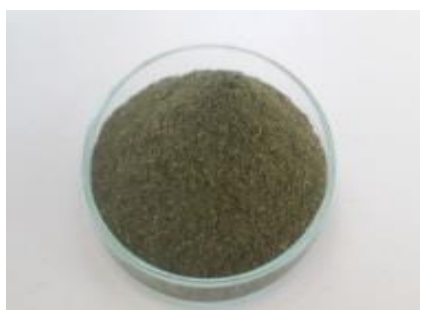

(a)

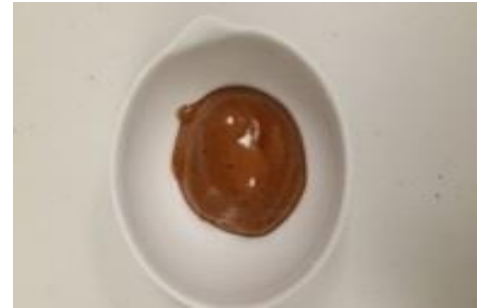

(b)

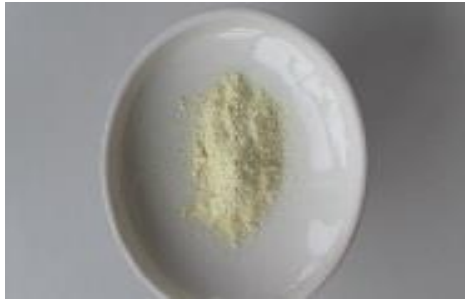

(c)

Figure 2: (a) ground Ocimum gratissimum leaves (b) A brown coloured paste and (c) $\mathrm{ZnO}$ nano powder sample after annealing .

This paste was then transferred into a ceramic crucible and annealed in a furnace at $250{ }^{\circ} \mathrm{C}$ for $3 \mathrm{hrs}$ giving zinc oxide $\mathrm{Og}$ I (250) nanoparticles. The same process was repeated with the Og I leaf extract, but the paste was now annealed at $400{ }^{\circ} \mathrm{C}$ for the same $3 \mathrm{hrs}$ to give zinc oxide Og I (400) nanoparticles. The annealing in the furnace helped to complete the oxidation of zinc oxide sample and remove any leaf extract material that may still be clinging to the surface of the $\mathrm{ZnO}$ nanoparticles. The obtained samples were labelled accordingly. This same procedure was repeated using Og II plant leaf extract and the brown paste was also annealed at $250{ }^{\circ} \mathrm{C}$ for $3 \mathrm{hrs}$ and labelled zinc oxide Og II (250) nanoparticles. The produced zinc oxide nanoparticles (powder) appearance is as shown in Figure 2c. These three samples were then characterised using UV-Vis spectrometer and X-ray diffraction (XRD). Fourier transform infrared spectroscopy (FTIR) scans were done for zinc oxide Og I(250) and zinc oxide Og II (250) nanoparticles to know the functional groups in the plant leaf extracts used which played a role in the nanoparticle synthesis. For zinc oxide Og I(250) and Og I(400) nanoparticles, photoluminescence studies were done. Their scanning electron microscopy (SEM) images were also taken to see the effect of annealing temperature on the nanostructures of the produced $\mathrm{ZnO}$ nanoparticles.

\section{Characterization of the nanoparticles}

The UV-Vis absorbance spectra of the zinc nanoparticles were obtained using the UV 2600 Shimadzu spectrophotometer equipped with ISR - 2600 integrating sphere attachment in the range 220-1400 nm. The absorbance spectra showed how light interacts with the samples and for each sample, the wavelength 
at which peak absorbance occurs was obtained. The diffuse reflectance spectra of the samples were also run and from it, values of $R$ were obtained. This was fed into the Kubelka-Munk function (Eq 1) given as:

$$
F(R)=\frac{(1-R)^{2}}{2 R}
$$

And from the Tauc relation (Eq 2):

$$
(h v \alpha)^{\frac{1}{n}}=A\left(h v-E_{g}\right)
$$

(where $h$ is a Planck constant, $v$ is the frequency of the light shone on the sample, $\alpha=\mathrm{F}(\mathrm{R})$ and $n=\frac{1}{2}$ for zinc oxide which is a direct band gap semiconductor [32]. )

Tauc plots which are graphs of $(F(R) E)^{2}$ against energy $e V$ ) were done using obtained data and a linear fit in the region of maximum change gave the optical band gap energy $E_{g}$ of the synthesized zinc oxide nanoparticles.

The SEM images of the nanoparticles were taken using JOEL JSM 6330F field emission scanning electron microscope which uses an accelerating voltage of about $10.0 \mathrm{kV}$ and current in the range $2 \mu \mathrm{A}-$ $10.5 \mu A$ with a working distance (WD) of about $7 \mathrm{~mm}$ and the nanoparticle size analysis was done using GATAN micrographs software.

The X-ray diffraction (XRD) scans were done to know the crystal structure of the $\mathrm{ZnO}$ nanoparticles. Using the BRUKER D8 Advance powder diffractometer with a $C u K \alpha$ source and $\lambda=$ $1.5418 \AA$ and with the slit set at $2 \mathrm{~mm}$ for a large beam and a sample rotation speed of $20 \mathrm{rpm}$, scans were performed with a step size of 0.02 degree for $2 \theta$ values between 25 and 75 degrees for $15 \mathrm{hrs}$. From the obtained X-ray diffraction pattern of each sample, and by using the Debye-Scherer's relation [32] given in $\mathrm{Eq}(3)$ the crystallite sizes of each of the zinc nanoparticles samples were determined.

$$
D=\frac{K \lambda}{B \operatorname{Cos} \theta}
$$

where $D$ is the crystallite size, $K$ is geometric factor assumed to be 0.9 for spherical particles, $\lambda$ is the wavelength of the X-ray shone on the sample $(0.154 \mathrm{~nm}), \theta$ is the diffraction angle, B is the Full width at half maximum (FWHM) in radians.

The FTIR scan was using Perkin Elmer Spectrum 100 spectrometer with an attenuated total reflectance (ATR) module was used and the scanning of two samples was done within the wavenumber range $600-4000 \mathrm{~cm}^{-1}$. The Photoluminescence spectra of zinc oxide Og I (250) and zinc oxide Og 1(400) nanoparticles were done at room temperature with an instrument which uses the $325 \mathrm{~nm}$ line of the Helium-cadmium (He-Cd) laser with a Renishaw RM-2000 spectrometer. The instrument which has a Peltier cooled Charge Couple Device (CCD) array and was set to $10 \%$ laser power, produced photo luminescence spectra of $\mathrm{ZnO}$ nanoparticles synthesized using same plant leaf extract concentration but annealed at two different temperatures (Figure 8). The aim was to see how the PL spectra of the $\mathrm{ZnO}$ nanoparticles changed with annealing temperature.

\section{RESULTS AND DISCUSSION}

\section{UV-Vis absorbance and diffuse reflectance spectrum}

The zinc oxide Og I (250) and zinc oxide Og II(250) nanoparticles absorbance spectra Figure 3 (a) show a surface plasmon resonance (SPR) peak at wavelength $372 \mathrm{~nm}$ though the Og II (250) has a higher absorbance of 1.4 than the $\mathrm{Og} \mathrm{I}(250)$ nanoparticles. 
The SPR wavelength for the zinc oxide Og 1(400) nanoparticles (Fig. 3b) was observed to be at $375 \mathrm{~nm}$ and therefore not significantly different from those of zinc oxide Og I (250) and zinc oxide Og II (250) nanoparticles though the absorbance of the latter was higher at 1.7. These SPR wavelength values are less than that of bulk zinc oxide given as $380 \mathrm{~nm}$ [33] and show a blue shift in excitonic absorption indicating a small quantum confinement effect [34].
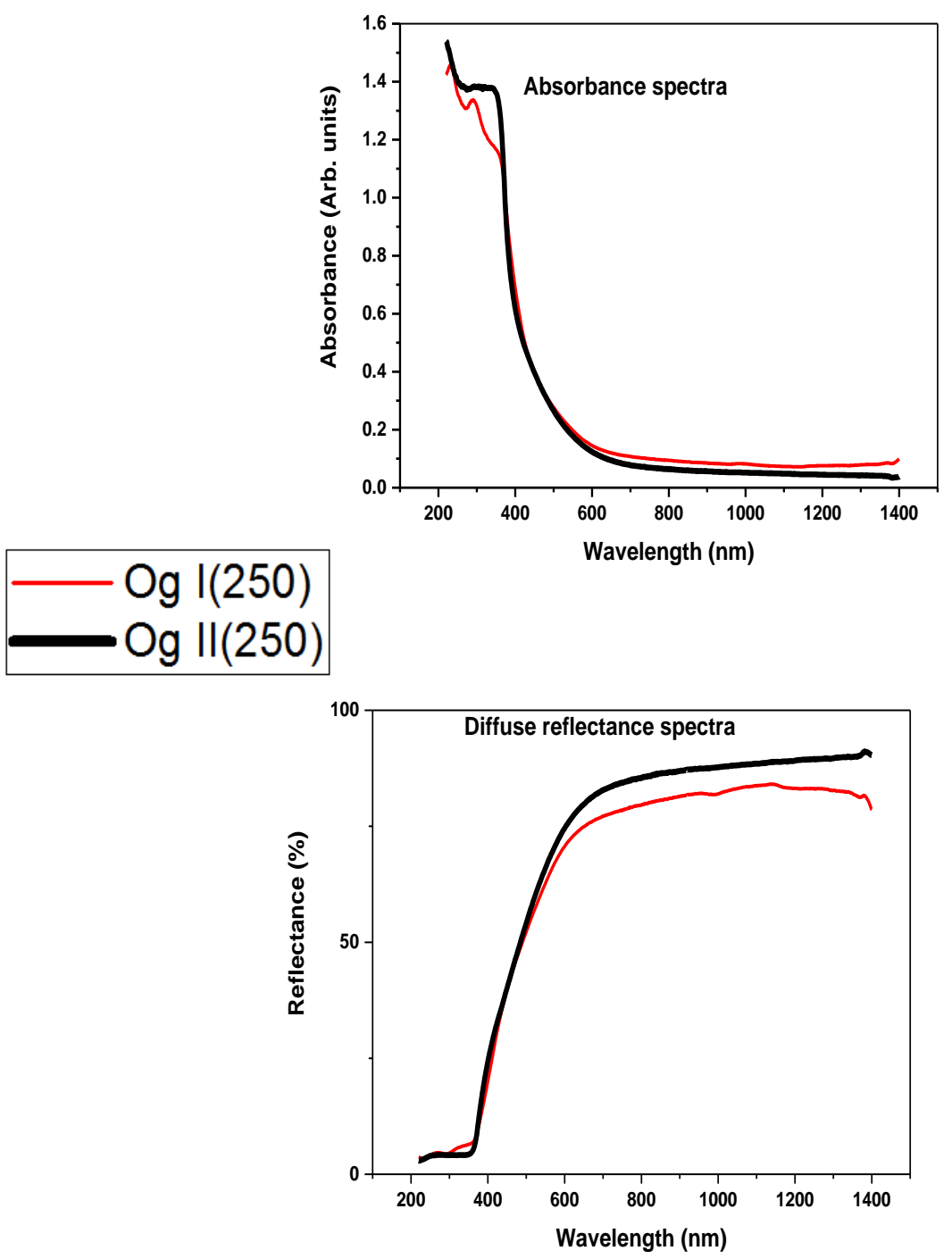

Figure 3: (a) Absorbance and diffuse reflectance spectra for zinc oxide Og I(250) and II (250) nanoparticles. 

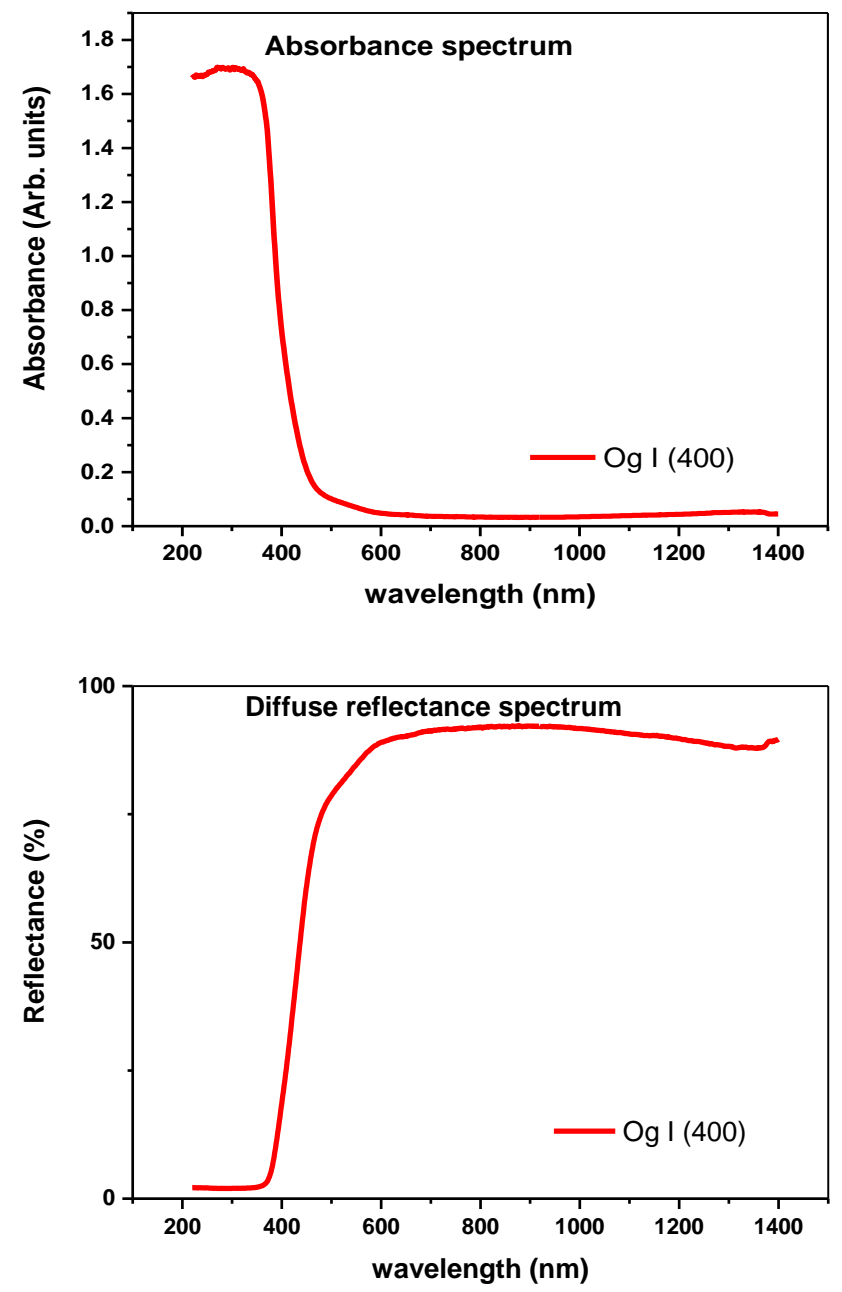

Figure3: (b) Absorbance and diffuse reflectance spectra for zinc oxide Og I (400) nanoparticles

From the Tauc plots of the three samples it was observed that increasing the plant leaf extract concentration used for the nanoparticle synthesis or raising the annealing temperature of the nanoparticles increased the optical energy bandgaps of the nanoparticles. With low plant leaf extract concentration, better stability of the nanoparticles is ensured hence better size control is achieved resulting in smaller nanoparticles with low optical energy bandgap $\left(E_{g}\right)$ and hence better conductivity [35]. Conversely, an increase in the leaf extract concentration creates some instability, encourages agglomeration leading to the formation of larger nanoparticles. The number of energy levels decreases resulting in an increased optical energy band gap and therefore nanoparticles which are poorly conducting $[35,36]$.This observation agrees with the blue shift in absorption spectra observed for the nanoparticles. Thus, the optical energy band gap $E_{g}$ values for the $\mathrm{ZnO}$ Og I (250), Og I (400) nanoparticles and $\mathrm{ZnO}$ Og II (250) nanoparticles were found to be $3.22 \mathrm{eV}, 3.24 \mathrm{eV}$ and $3.31 \mathrm{eV}$ respectively (Figure 4) implying that increasing the annealing temperatures of the $\mathrm{ZnO}$ nanoparticles or the concentration of the plant leaf extract used increases the optical energy bandgap of the nanoparticles. This outcome agrees with reports by Mallika et al, and Nithya and Kalyanasundharam respectively [37,38]. Thus, low annealing temperatures produced $\mathrm{ZnO}$ nanoparticles with low optical energy band gap implying more free electrons and hence increased conductivity [39]. 

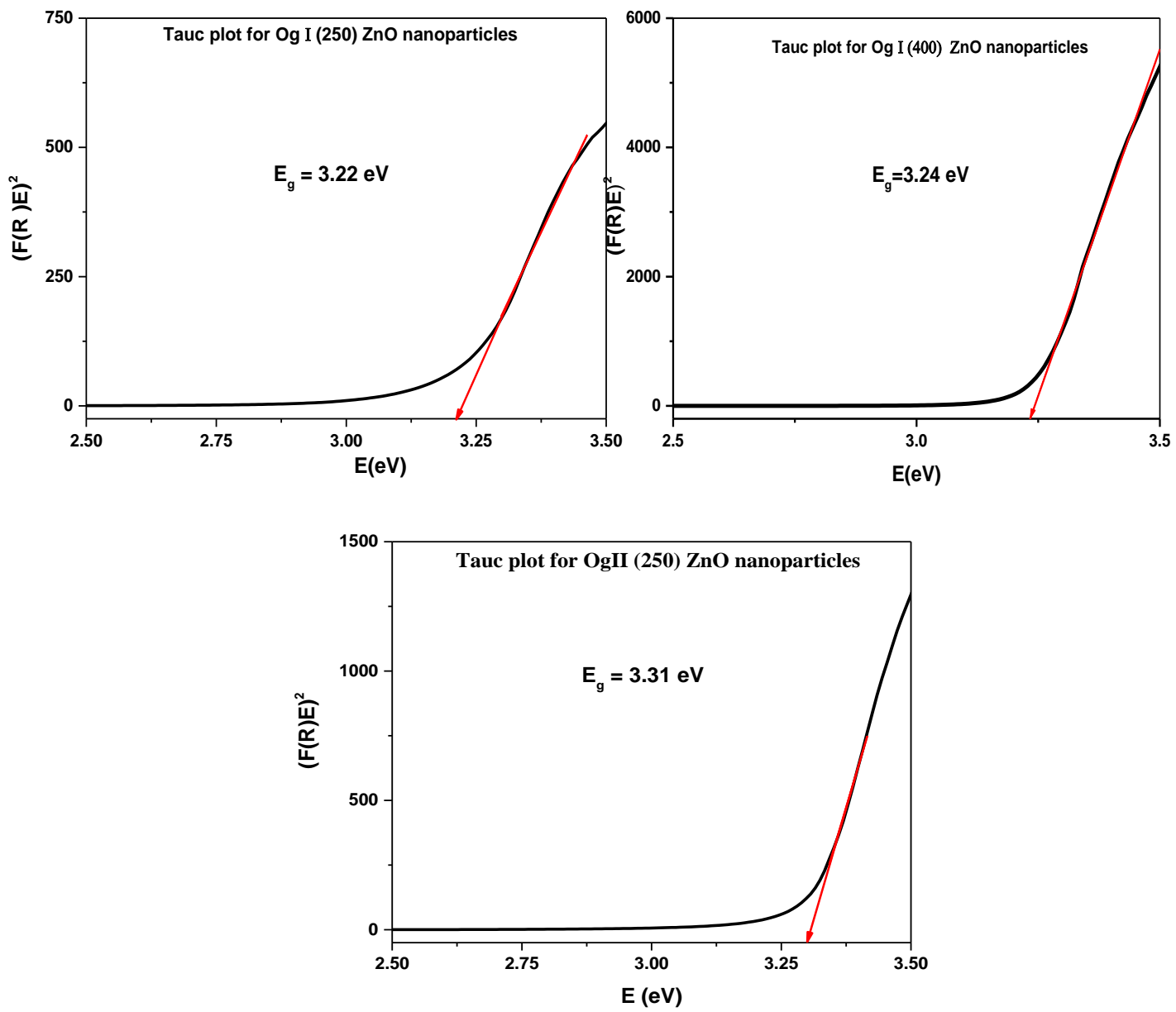

Figure 4: The Tauc plot for (a) Og I (250), Og I (400) and Og II (250) samples. The red line shows the linear fit to obtain the $E_{g}$ values

\section{Scanning electron microscopy}

The SEM images (Figure 5) of the synthesized zinc oxide nanoparticles show them to be spherical in shape and polydispersed. The $\mathrm{ZnO}$ Og I (400) nanoparticles were found to be of a wide range of sizes with smaller nanoparticles clustering around bigger micrometre sized particles with sharp edges suggesting that this high annealing temperature might have resulted in the sintering of some of the nanoparticles.

The zinc oxide Og I (250) nanoparticles were also spherical in shape, clustered together, but had porous surfaces and sizes in the micrometre range. Such porous structures according to Rodnyi and Khodyuk [40] could qualify them for use in gas sensor applications. 


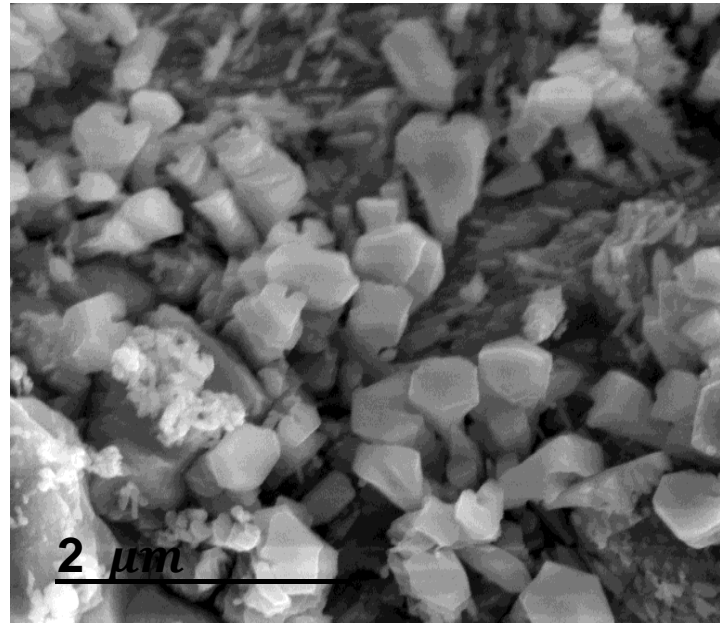

a

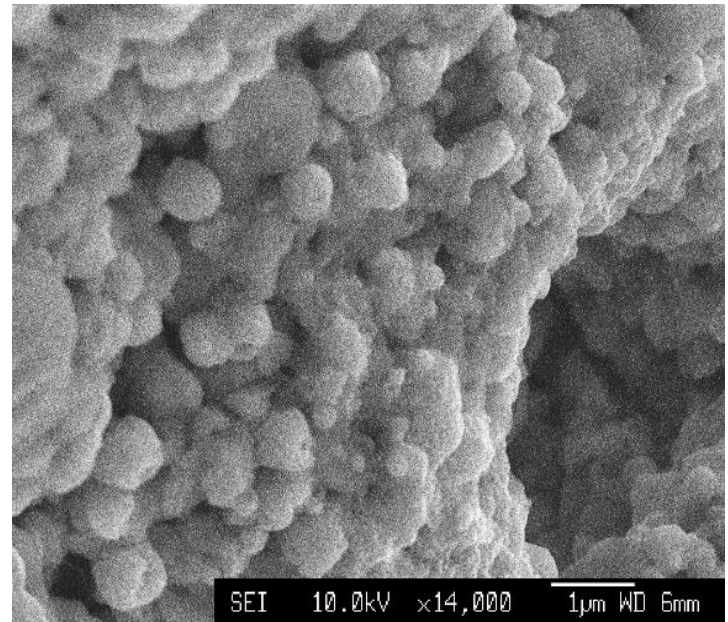

b

Figure 5: SEM micrograph of (a) ZnO nanoparticles from Og I (400) sample and (b) Og I (250) sample

\section{$X$-ray diffraction}

The X-ray powder diffraction showed Bragg peaks whose intensities increased with a raise in annealing temperatures of the $\mathrm{ZnO}$ nanoparticles (Figure 6). The XRD pattern for all the $\mathrm{ZnO}$ nanoparticles had peaks which were typical of the hexagonal wurtzite ZnO structure (JCPDS (2000)36-1451). [41] No other phases were observed in the XRD spectra either from impurities or $\mathrm{ZnO}$ polymorphs, however for the $\mathrm{Og}$ II (250) sample (Figure $6 \mathrm{c}$ ) a slight shift in the $2 \theta$ Bragg peaks towards higher values was observed and the 004 peak was missing. For each XRD pattern and for the 100 plane and using the Scherer equation, the $\mathrm{ZnO}$ Og I (400) nanoparticles crystallite size was calculated to be $29 \pm 0.02 \mathrm{~nm}$, while those of the $\mathrm{ZnO}$ Og I (250) and Og II (250)nanoparticles were calculated to be $14 \pm 0.03 \mathrm{~nm}$ and $17 \pm 0.02 \mathrm{~nm}$ respectively.Thus raising the annealing temperature or plant leaf extract concentration produced larger crystallites and agrees with report by Mallika et al [37] and Nithya and Kalyanasundharam [38]. Furthermore, the ZnO Og I (400) nanoparticles, lattice constant was calculated to be $\mathrm{a}=\mathrm{b}=2.82 \AA$ and $\mathrm{c}$ $=4.60 \AA$, while that of $\mathrm{ZnO}$ Og I (250) nanoparticles was found to be $\mathrm{a}=\mathrm{b}=2.80 \AA$ and $\mathrm{c}=4.40 \AA$ 
a

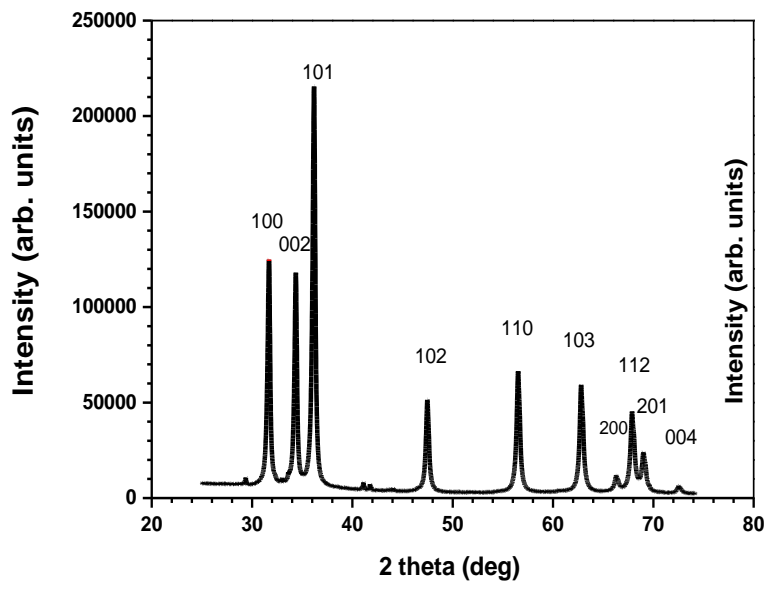

b

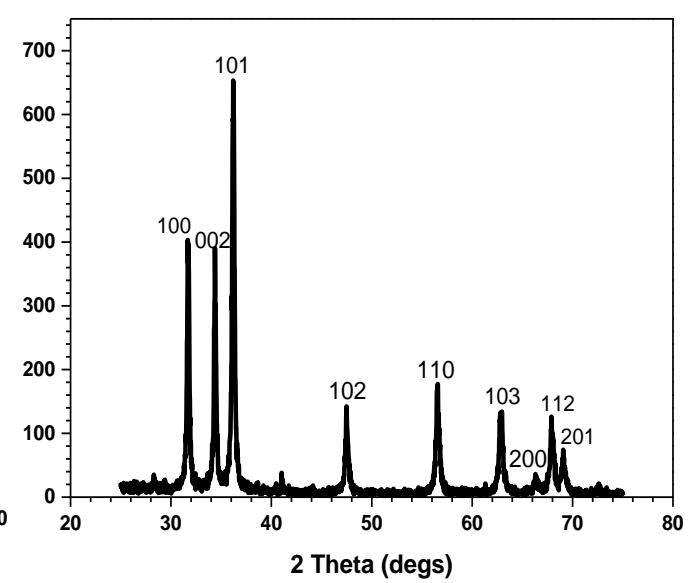

c

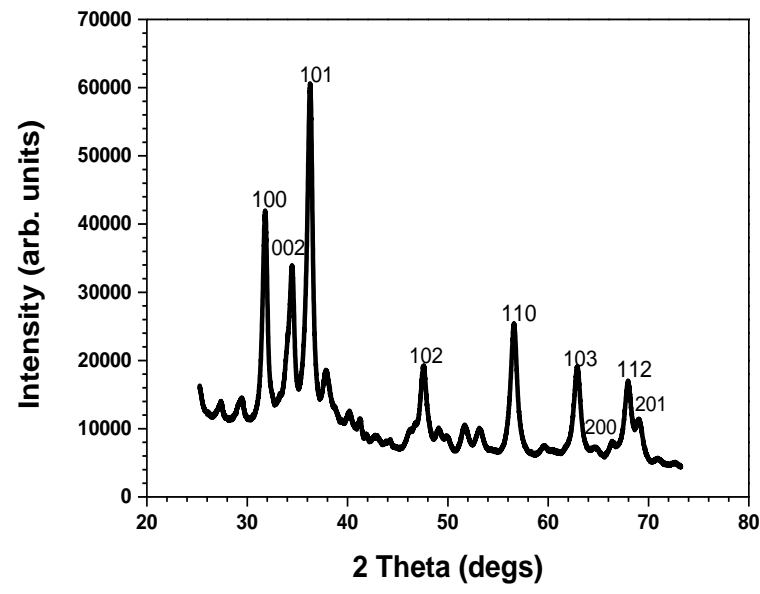

Figure 6: XRD for (a) ZnO Og I (400) (b) ZnO Og I (250) and (c) ZnO Og II (250) nanoparticles.

\section{Fourier transform infrared spectroscopy}

The FTIR reflectivity spectra of two samples scanned (Figure 7) show six prominent IR bands. A sharp peak at $3386 \mathrm{~cm}^{-1}$ represents the $\mathrm{O}-\mathrm{H}$ stretch bond of alcohols and the broad peak at $3500 \mathrm{~cm}^{-1}$ is for the N$\mathrm{H}$ stretching of phenols and primary amine. The strong peak at $1643 \mathrm{~cm}^{-1}$ is for the $\mathrm{C}=\mathrm{C}$ stretch for alkenes while the peaks at $1320 \mathrm{~cm}^{-1}$ and $1377 \mathrm{~cm}^{-1}$ represent the $\mathrm{O}-\mathrm{H}$ bending of phenols. The $816 \mathrm{~cm}^{-1}$ peak is for an aromatic compound and shows the $\mathrm{C}-\mathrm{H}$ bending of aldehyde. From these results, the identified reducing agents are the Amines, phenols and aldehydes which probably played a role in the nanoparticles synthesis. 


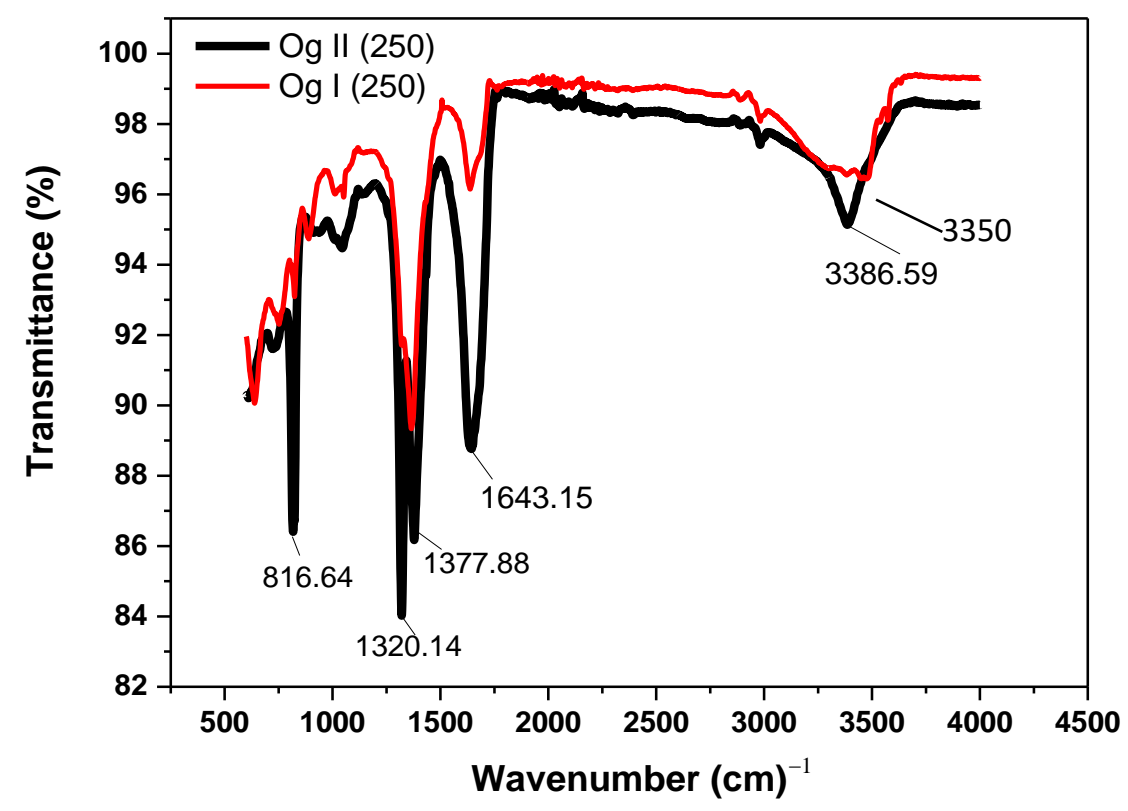

Figure 7: FTIR spectra of Og I and Og II zinc oxide nanoparticles annealed at $250{ }^{\circ} \mathrm{C}$

\section{Photoluminescence (PL)}

The photoluminescence spectra for the $\mathrm{ZnO}$ Og I (400) and Og I (250) nanoparticles show that the nanoparticles have band edge photoluminescence (Figure 8). Two emission peaks namely a strong and sharp emission peak at shorter wavelengths (UV emission peaks) located at $369 \mathrm{~nm}$ and $381 \mathrm{~nm}$ for the $\mathrm{ZnO}$ Og I (400) and Og I (250) nanoparticles respectively corresponding to the near bandgap excitonic emission [42] and the broader emission peaks around $538 \mathrm{~nm}$ and $523 \mathrm{~nm}$ characteristic of the green emission bands are probably from point defects due to singly ionized oxygen vacancies. [32] The UV emission observed to be less than $400 \mathrm{~nm}$ and usually described as band edge emission is due to a recombination of free excitons when they collide with one another. [43]

The PL intensities of the nanoparticles were dependent on their annealing temperatures. While the PL intensity of the $\mathrm{ZnO}$ Og I (400) nanoparticles decreased with an emission peak shifted towards lower wavelengths, that of the $\mathrm{ZnO}$ Og I (250) nanoparticles increased and appeared at a higher wavelength (Figure 8). 


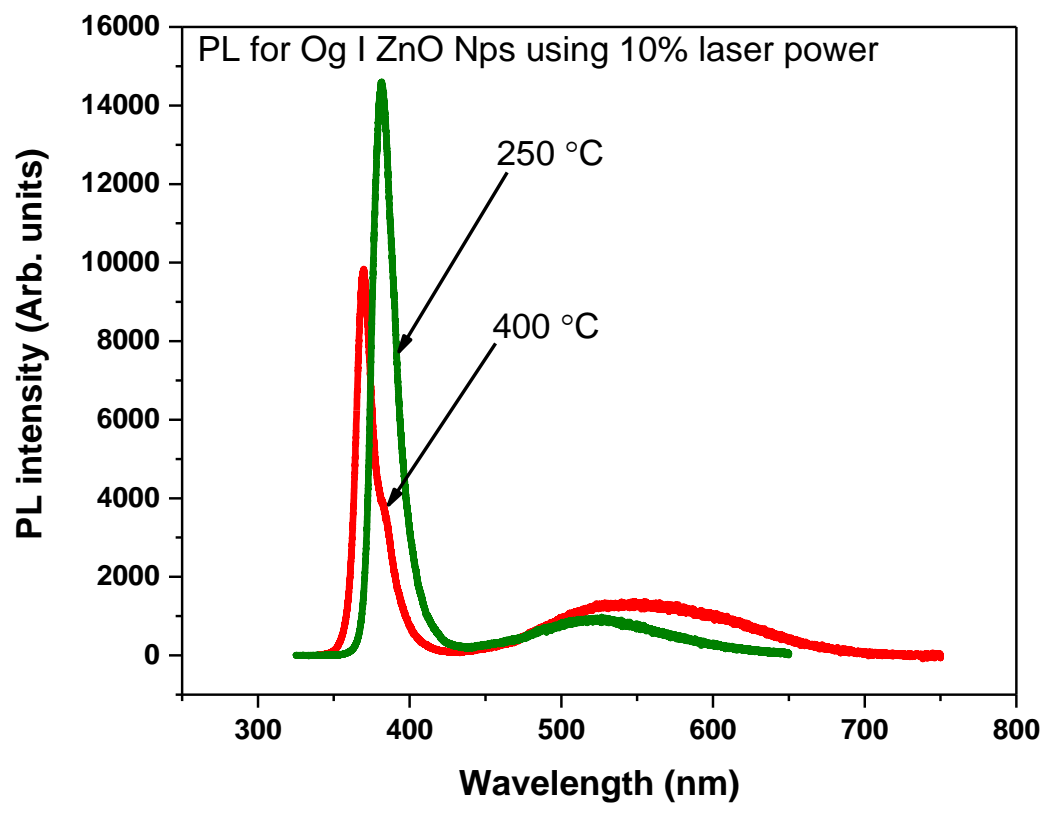

Figure 8: Photoluminescence of Og I (250) and Og I (400) ZnO nanoparticles

\section{CONCLUSIONS}

Zinc oxide nanoparticles were synthesized using two concentrations of Ocimum gratissimum plant leaf extracts and zinc nitrate hexa-hydrate. The derived $\mathrm{ZnO}$ nanoparticles were annealed at $250{ }^{\circ} \mathrm{C}$ and later at $400{ }^{\circ} \mathrm{C}$.

The UV-Vis absorbance spectra gave absorbance peaks at 372-375 $\mathrm{nm}$ showing a blue shift in excitonic absorption and small confinement. The optical energy band gap of the nanoparticles increased when the annealing temperature or concentration of the Ocimum gratissimum plant leaf extract used is increased. The $\mathrm{X}$-ray diffraction pattern of the $\mathrm{ZnO}$ nanoparticles shows them to have good crystalline structure and are of the hexagonal wurtzite structure. Though applying an annealing temperature of $400{ }^{\circ} \mathrm{C}$ increased the crystallite size of the nanoparticles from $14 \mathrm{~nm}-29 \mathrm{~nm}$, it resulted in the sintering of some nanoparticles as the SEM images reveal. Conversely the lower annealing temperature of $250{ }^{\circ} \mathrm{C}$ when used created lower optical energy band gap nanoparticles which means better conductivity. The FTIR spectra identified phenols, amines and aldehydes as the reducing agents which probably played a role in the nanoparticle synthesis. The photoluminescence spectra of the $\mathrm{ZnO}$ nanoparticles showed strong near band edge emission peaks with a spectral shift towards longer wavelengths at lower annealing temperatures. This work shows that the optical properties of zinc oxide nanoparticles can be changed by varying either the leaf extract concentration used or the annealing temperature used for the nanoparticles.

\section{POTENTIAL CONFLITS OF INTERESTS}

"The authors declare that there is no conflict of interest in this work and article" 


\section{ACKNOWLEDGEMNT}

The authors are very grateful to the School of Chemistry, University of Bristol, for granting them access to their UV-Vis (UV Shimadzu 2600) spectrophotometer, BRUKER D8 XRD machine, and Scanning electron microscope and I also thank the management of Federal University of Lafia (Nigeria) who through the Tertiary Education Trust Fund (TETFund) sponsored my PhD programme at the University of Bristol, UK.

\section{REFERENCES}

[1] Mohammad V, Umar A, Hahn Y-B, (2010) ZnO Nanoparticles; Growth, Properties and Applications. Metal oxide and nanostructures and their applications Chapter 4, American Scientific Publishers: 1-36

[2] Hossain MK, Minelli A, Sadaf F, Ulfa M (2014) Synthesis and Optical Characterization of morphologically different $\mathrm{ZnO}$ nanoparticles and their interaction with hydrogen, nan. O mat. Master, pp 1-11, 2014

[3] Soosen S.M, Bose L, George K.C (2009) Optical properties of ZnO Nanoparticles SB Academic review XVI (1,2): 57-65

[4] Quin L, Shing C, Sawyer S, Dutta P (2011) Enhanced ultraviolet sensitivity of zinc oxide nanoparticle photoconductors by surface passivation Optical materials Elsevier 33: 359-362

[5] Espitia P., Otoni C.G. et al, (2012) ZnO nanoparticles: Synthesis, Antimicrobial activity and food packaging applications. Food and Bioprocess Technology Vol 5(5): 1447-1464 Espitia PJP, Soares N.F.F Combra JSR et al https://doi.org/10.1007/s 11947-012-07976-6

[6] Selvi, MT, K Nancy, J Felicita Florence, A study on the effect of pharmacologically active Lawsonia Inermis Linn leaf extract on zinc electrodeposition on mild steel. International journal of research and development in Pharmacy and life sciences, 2015.4(1):1362-1370.

[7] Rameshaiah, G., J. Pallavi, and S. Shabnam, Nano fertilizers and nano sensors-an attempt for developing smart agriculture. Int J Eng Res Gen Sci, 2015. 3(1): p. 2091-2730.

[8] Sidra, S., Muhammad, A., Chaudhari, S.K, (2014) Zinc oxide nanoparticles for revolutionizing Agriculture; Synthesis and Applications (articles ID 025494) Hindawi Publishers, 2014, 1-8

[9] Mfon R.E, Odiaka N.I., Sarua A (2017) Interactive effect of colloidal solution of zinc oxide nanoparticles biosynthesized using Ocimum gratissimum and Vernonia amygdalina leaf extracts on the growth of Amaranthus cruentus seeds. African Journal of Biotechnology Vol 16(26): 1481-1489

[10] Ero, A., Okur, S., Comba, B., Mermer, O., Arikan, M.C. (2010) Humidity sensing properties of ZnO nanoparticles synthesized by Sol-gel process. Elsevier Science Direct, B145: 174-180

[11] Abdullah K.A., Awad S., Zaraket J., Salame C., Synthesis of ZnO nanopowders by using Sol-Gel and Studying their structural and Electrical properties at different temperature, Energy Procedia 119(2017): 565-570)

[12] Agarwal H., Rajeshkumar S., (2017) A review on gren synthesis of zinc oxide nanoparticles- An ecofriendly approach, Resource-Efficient Technologies 3(4): 406-413

[13] Malik P, Shankar R, Malik V, Sharma N, Mukherjee TK (2014) Green chemistry based benign routes for nanoparticle synthesis J. nanopart. 2014: https://doi:10.1155/2014/302429

[14] Egorova E.M., Revina A.A., (2000) Synthesis of metallic nanoparticles in reverse micelles in the presence of quercetin. Colloids Surf. A Physicochem Eng. Asp. 168: 87-96

[15] Yasin S., Liu L., Yao J. (2013) Biosynthesis of silver nanoparticles by Bambo leaves extract and their antimicrobial activity. Journal of Fibre Bio engineering and informatics 6(1):77-84

[16] Dixon R.A., Pasinetti G.M (2010) Flavonoids and Isoflavonoids from plant Biology to Agriculture and neuroscience plant physiol. 154(2): 453-457

[17] Mittal A.K., Chisti Y., Banerjee U.C (2013) Synthesis of metallic nanoparticles using plant extracts. Elsevier Biotechnology Advances 13(2): 346-356

[18] Dubey M., Bhadauria S., Kushwah B (2009) Green synthesis f Nano silver particles from extract of Eucalyptus hybrid (safeda) leaf. Dig.J. Nanomater. Biostruct. 4: 537-543

[19] Huang J.L., Li Q.B., Sun D.H., Lu Y.H., Su Y.B., Yang X et al (2007) Biosynthesis of Silver and Gold nanoparticles by novel sundried Cinnamomum camphora leaf. Nanotechnology 18, 2007.

[20] Makarov VV, Love AJ, Sinitsyna OV, Makarov SS, Yaminsky I.V, Taliansky ME and Kalinina NO (2014) Green Nanotechnologies: Synthesis of metal nanoparticles using plants. Acta Naturae 6(1): 35-44

[21] Ahmed S, Ahmad SM, Swami BL Ikram S (2016) green synthesis of silver nanoparticles using Azadirachta indica. aqueous leaf extract. Journal of Radiation research 9(1):1-7 
[22] Sangeetha G, Rajeshwari S, Venckafesh R, (2011) Green synthesis of zinc oxide nanoparticles by aloe barbadensis miller leaf extract:structure and optical properties, Materials Research Bulletin 46(2011): 2560 2566

[23] Raut S, Thorat P.V., Thakre R., (2015) Green synthesis of zinc oxide nanoparticles using Ocimum Tenuiflorum leaves, IJSR, 4(5): 1225-1228

[24] Salam H.A., Sivaraj R., Rajendran V,(2014) Green synthesis and characterisation of zinc oxide nanoparticles fromm Ocimum basilicum L var, purpurasceris Benrith-Lamiaceae leaf extract, Materials letters 131: 16-18

[25] Narendra K., Chandra H.K., Mohana N., Nuthan B.R et al (2019) Phyto-mediated synthesis of zinc oxide nanoparticles using aqueous plant extract of Ocimum americanumm and evaluation of its bioactivity, S,N Applied Sci 1651 https://doi10.1007/s42452-019-0671-5

[26] Ramana M.V., Anuradha G., Rao V.V.J.R., Anitha P., Lakshmi P.S. (2013) Synthesis of zinc oxide Nanostructures suing Ocimum gratissimum leaf extract IJSR: 140-143

[27] Dare EO, Oseghale CO, Labulo AH, Adesuji ET, Elemike EE, Onwuka J, Bamgbose T, Green synthesis and growth kinetics of nanosilver, Springer J. Nanostruct. Chem (5) pp 85-94, 2014

[28] Rabelo, M., Souza, E.P., Soare, P.M.G.(2003) Antinociceptive properties of the essential oil of Ocimum gratissimum L (Lubiatae) in mice, Braz. J Med Biol. Res :36:521-524

[29] Kabir, O.A, Olukayode, O, Chidi, E.O, Ibe, Christopher C I, and Kehinde, A.F.(2005) Screening of crude extracts of six medicinal plants used in South-West Nigeria unorthodox medicine for anti-methicillin resistant Staphylococcus aureus activity. BMC complementary and Alternative Medicine, 5:6: 1-7

[30] Prabhu, K.S., Lobo, R., Shirwaikar, A.A., and Shirwaikar, A.(2009) Ocimum gratissimum: A Review of its chemical, Pharmacological and Ethnomedicinal Properties The open complementary medicine journal. 1: $1-15$

[31] Ijeh, I.I., Omodamiro, O.D., Nwanna, I.J.(2005) Antimicrobial effects of aqueous and ethanolic fractions of two species Ocimum gratissimum and Xylopia aethiopica. Afr. J. Biotech, 4: 953-956

[32] Hossain, Md K., Minelli, A., Sadaf, F., Ulfa, M.(2014) Synthesis and Optical characterisation of morphologically different ZnO Nano powders and their interaction with hydrogen, nano Mat. 1-11

[33] Liqiao, Q., Christopher, S., Sawyer, S., Dutta, P.S.(2011) Enhanced ultra-violet sensitivity of Zinc oxide nanoparticles photoconductors by surface passivation. Elsevier Optical Materials (933), 359-362

[34] Koch, U., Fojtik, A., Weller, H., Henglein, A.(1985) Photochemistry of semiconductor colloids preparation of extremely small ZnO par-SAO/NASA ADS. Chemical Physics Letters, 122(5), 507-510

[35] Soto-Robes C.A., Lugue P.A., Gomeez-Gutierrez C.M., Nava O., Vilchis-Nestor A.R., Lugo-Medina E., Ranjithkumar R., Castro-Beltran A., (2019), Study on the effect of the concentration of Hibiscus sabdariffa extract on the green synthesis of ZnO nanoparticles, Results in Physics, 15(2019)102807

[36] Fendler J.H., (2008) Nanoparticles and Nanostructured films: Preparation, Characterization and Applications. John Wiley \&Sons, 2008 ISBN: 3527612068,9783527612062:488

[37] Mallika A.N., Reddy A.R., and Reddy K.V (2015) Annealing effects on the structural and optical properties of $\mathrm{ZnO}$ nanoparticles with PVA and CA as chelating agents, J Adv. Ceramic 4(2): 123-129. https://doi:10.1007/s40145-015-01 42-4

[38] Nithya K., Kalyanasundharam S., (2018) Effect of chemically synthesis compared to biosynthesized ZnO nanoparticles using aqueous extract of C. halicacabum and their antibacterial activity, Open Nano Vol4 2019, 100024 https://doi.org/10.1016/jo.nano.2018.10.001

[39] Zhang G., Lu K., Zhang X., Yuan W., Shi M., Ning H, Tao R., Lui X., Yao R., and Peng J.,(2018) Effects of annealing temperature on optical band gap of sol-gelTungsten trioxide films, Micromachine, 9(8): 377

[40] Rodnyi, P.A., Khodyuk, I.V.(2011) Optical and Luminescence properties of Zinc Oxide optics and spectroscopy, Vol III No 5, 776-785

[41] Vitalij, K.P and Zavalij, P.Y (2005) Fundamentals of powder diffraction and structural characterisation of materials. Springer

[42] Sangeetha, G., Rajeshwari, S., Venckatesh, R(2011) Green synthesis of zinc oxide nanoparticles by aloe barbadensis miller leaf extract: Structure and optical properties. Mater. Res. Bull. 46(12):2560-2566.

[43] Chithra, M.J., Sathya, M., Pushpanathan, K.(2015) Effect of pH on crystal size and photoluminescence property of $\mathrm{ZnO}$ nanoparticles prepared by chemical precipitation method. Acta metallurgica sinica (English Letters), 28(3): 394-404 https://doi:10.1007/s40195-015-218-8 